\title{
ACCESS OF PERSONS WITH INTELLECTUAL DISABILITIES (PwID) TO MENTAL HEALTH CARE
}

João Albuquerque, Centro de Recuperação de Menores, Irmãs Hospitaleiras do Sagrado Coração de Jesus, Assumar, Portugal

\footnotetext{
PERSONS WITH INTELLECTUAL DISABILITIES:

- present atypical psychopathology,

- may not perceive any suffering or malaise as a

sign of disease,

- when able to perceive it, have difficulty

expressing or explaining what they feel.
}

REHABILITATION PROFESSIONALS,

who usually support PwID:

- are only trained in social intervention

and rehabilitation, and not in

psychiatric pathology,

- therefore do not have the knowledge

to identify and diagnose clinical situations associated with ID

MENTAL HEALTH SERVICES AND PROFESSIONALS do not adapt their dynamics to the particularities of PwID
MENTAL HEALTH PROFESSIONALS:

- do not have specific training in ID,

- which leads to a devaluation of the complains presented by either PwID or the technicians who accompany them,

- consider any complaint as a manifestation of ID,

- do not identify the symptoms because they are atypical and stereotyped,

- fail to achieve effective therapeutic intervention, when attempted .

\section{How to change this reality?}

CLINICAL SETTING:

- Same context and space of the general population;

- Simplified paper work;

- Avoid long waiting time;

- Patient accompanied by meaningful persons from every

life context;

- If patient is confident, take some time to be alone with

him/her;

- Never give up (to communicate, to do better, ...);

- Consider that everybody needs to be heard, including the patient.

\section{Reach PwID Mental \\ Health Needs}

PROFESSIONALS (both social and mental health settings):

- Include PwID health problems in college curricula

- Learn to respect each others perspectives and ideas;

- Search specific education on mental health problems in PwID (DoubleDiagnosis (DD));
FAMILYS AND PwID:

- Empowerment, improving self-esteem and confidence

- Self-Advocacy, manifesting needs and expectations, participating in decision making process. 